\title{
Phylogeny of Flavobacteria Group Isolated from Freshwater Using Multilocus Sequencing Analysis
}

\author{
Seyoung Mun ${ }^{1}$, Jungnam Lee ${ }^{1 \dagger}$, Siwon Lee ${ }^{2}$, Kyudong Han ${ }^{1}$, Tae-Young Ahn ${ }^{3 *}$ \\ ${ }^{1}$ Department of Nanobiomedical Science \& BK21 PLUS NBM Global Research Center for Regenerative Medicine, \\ Dankook University, Cheonan 330-714, Korea, ${ }^{2}$ Plant Quarantine Technology Center, Animal and \\ Plant Quarantine Agency, Suwon 443-440, Korea, ${ }^{3}$ Department of Microbiology, Dankook University, Cheonan 330-714, Korea
}

Sequence analysis of the $16 \mathrm{~S}$ rRNA gene has been widely used for the classification of microorganisms. However, we have been unable to clearly identify five Flavobacterium species isolated from a freshwater by using the gene as a single marker, because the evolutionary history is incomplete and the pace of DNA substitutions is relatively rapid in the bacteria. In this study, we tried to classify Flavobacterium species through multilocus sequence analysis (MLSA), which is a practical and reliable technique for the identification or classification of bacteria. The five Flavobacterium species isolated from freshwater and 37 other strains were classified based on six housekeeping genes: gyrB, dnaK, tuf, murG, atpA, and glyA. The genes were amplified by PCR and subjected to DNA sequencing. Based on the combined DNA sequence $(4,412 \mathrm{bp})$ of the six housekeeping genes, we analyzed the phylogenetic relationship among the Flavobacterium species. The results indicated that MLSA, based on the six housekeeping genes, is a trustworthy method for the identification of closely related Flavobacterium species.

Keywords: Flavobacterium, multilocus sequence typing, phylogeny

\section{Introduction}

Flavobacterium is a genus of gram-negative bacteria belonging to the family Flavobacteriaceae (order: Flavobacteriales, class: Flavobacteria, phylum: Bacteroidetes) [1]. The term Flavobacterium was first introduced by Bergey et al. in 1923 [1]. Since then, a number of Flavobacterium species have been identified, and the classification of the genus has been continuously amended. At present, it is widely accepted that the genus Flavobacterium contains bacteria that are yellow-pigmented, aerobic, and generally rod-shaped [2], and some Flavobacterium species mobilize through a gliding motility mechanism [3]. Flavobacterium strains could be isolated from various habitats, including freshwater, soil, plants, and food $[3,4]$.

The 16S rRNA gene has been widely used in many studies concerned with the identification or classification of microorganisms. However, using only one housekeeping gene as a single marker is not enough to distinguish some bacterial species, especially when they are closely related. In addition, gene-specific changes caused by horizontal gene transfer or recombination could be an obstacle to the phylogenetic studies that are based on a single gene marker $[5,6]$. To overcome the limitation, multilocus sequence analysis (MLSA) has been proposed as an alternative method in many studies. In reality, MLSA is a microbial genotyping method used to characterize a variety of microorganisms, including the genera of Pantoea [7], Bifidobacterium [8], Borrelia [9], Bradyrhizobium [10], and Bacteroides [11]. In MLSA, approximately seven housekeeping genes are required, but a standard for the given number and size of genes has not been established. This concise approach is based on concatenated sequences of multiple housekeeping genes, uses the concatenated sequences to identify the phylogenetic aspects of desired species, and investigates the patterns of genotypes between each species cluster [12].

This study was designed to classify the genetic diversity of collected Flavobacterium species. In addition, we also inve- 
stigated their relationship using phylogenetic analysis and compared the results for phylogenetic markers.

\section{Methods}

\section{Bacterial isolates}

Seven Flavobacterium isolates were collected. The two Flavobacterium reference strains, F. aquatile ATCC 11947 and F. frigidimaris F3-JCM12218, were purchased from the Japan Collection of Microorganisms (JCM), and five Flavobacterium isolates - F. koreense ARSA-15, F. koreense ARSA-19, F. koreense ARSA-42, F. chungnamense ARSA-103, and F. chungnamense ARSA-108-were previously isolated from the Cheon-ho reservoir in the Korea $[13,14]$.

\section{Bacterial growth and genomic DNA isolation}

This seven strains were cultured on R2A medium (Difco, Detroit, MI, USA) for 5 days at $25^{\circ} \mathrm{C}$ and produced creamyellow, semi-transparent colonies. We extracted genomic DNA from the seven Flavobacterium strains using the Wizard genomic DNA purification kit (Promega, Madison, WI, USA), according to the manufacturer's instruction.

\section{Polymerase chain reaction}

Through a PCR assay, we amplified seven housekeeping genes from the bacteria: 16S rRNA (16S ribosomal RNA) gene, atpA (ATP synthase alpha subunit), dnaK (molecular chaperone protein), glyA (serine hydroxy-methyltransferase), gyrB (DNA gyrase, subunit B), murG (N-acetylglucosaminyl transferase), and tuf (elongation factor $\mathrm{Tu}$ ). For the PCR amplification of the genes, we used primers designed in a previous study [15]. However, we failed to amplify the dnaK and atpA genes through PCR with the previously designed primers. Thus, we manually designed new PCR primers to amplify these two genes. The primers are listed in Table 1. PCR amplification of each gene was performed in a $25-\mu \mathrm{L}$ reaction volume using $10 \mu \mathrm{L}$ of a DNA polymerase kit (TaKaRa EmeraldAmp GT PCR Master Mix; TaKaRa, Ohtsu, Japan), 200 nM of each oligonucleotide primer, and 50 ng of template DNA. The PCR conditions were an initial denaturation at $95^{\circ} \mathrm{C}$ for $5 \mathrm{~min}$; followed by 35 cycles of $30 \mathrm{~s}$ of denaturation at $95^{\circ} \mathrm{C}, 30 \mathrm{~s}$ of annealing at $55^{\circ} \mathrm{C}$, and $2 \mathrm{~min}$ of extension at $72^{\circ} \mathrm{C}$; and followed by $5 \mathrm{~min}$ of a final extension at $72^{\circ} \mathrm{C}$. Two microliters of the resulting PCR products was loaded on a $1 \%$ agarose gel, stained with ethidium bromide, and visualized using UV fluorescence. The remaining PCR products were purified with the Wizard SV gel and PCR clean-up kit (Promega, Madison, USA) according to the manufacturer's instruction and sequenced on an ABI 3130XL automated DNA sequencer (Applied Biosystems, Foster City, CA, USA).

\section{DNA sequences analysis}

For each of the seven genes, we aligned the DNA sequences obtained from the seven Flavobacterium isolates using the software BioEdit, version 7.0 (http://www.mbio. ncsu.edu/Bioedit/bioedit.html/). After that, the housekeeping gene sequences of the 14 added reference strains were collected using BLAST (http://blast.ncbi.nlm.nih.gov/) and aligned in the same way.

Table 1. Primers used for multilocus sequence analysis of the Flavobacterim species in this study

\begin{tabular}{|c|c|c|c|c|c|c|}
\hline Gene & Gene product & Primer & Sequence $\quad\left(5^{\prime} \rightarrow 3^{\prime}\right)$ & $\begin{array}{l}\text { Amplicon } \\
\text { size (bp) }\end{array}$ & $\begin{array}{l}\text { Analyzed } \\
\text { size (bp) }\end{array}$ & Reference \\
\hline \multirow[t]{2}{*}{ gyrB } & DNA gyrase, subunit B & gyrB_F & TTGTAATGACTAAAATTGGTGC & 1,042 & 555 & Nicolas et al. [15] \\
\hline & & gyrB_R & GCCGAATCTCCCTCGACAAG & & & \\
\hline \multirow[t]{3}{*}{ dnak } & Molecular chaperone protein & dnaK_F & AAGGTGGAGAAATTAAAGTAGG & 1,070 & 680 & Nicolas et al. [15] \\
\hline & & dnaK_AF & GCTGAAGACTATTTAGGTC & 828 & & This study \\
\hline & & dnaK_R & CCACCCATAGTTTCGATACC & & & Nicolas et al. [15] \\
\hline \multirow[t]{2}{*}{ tuf } & Elongation factor $\mathrm{Tu}$ & tuf_F & GAAGAAAAAGAAAGAGGTATTAC & 982 & 833 & Nicolas et al. [15] \\
\hline & & tuf_R & CACCTTCACGGATAGCGAA & & & \\
\hline \multirow[t]{2}{*}{ murG } & $\mathrm{N}$-acetylglucosaminyl transferase & murG_F & TGGCGGTACAGGAGGACATAT & 870 & 725 & Nicolas et al. [15] \\
\hline & & murG_R & GCATTCTTGGTTTGATGGTCTTC & & & \\
\hline \multirow[t]{3}{*}{ atpA } & ATP synthase alpha subunit & atpA_F & CTTGAAGAAGATAATGTGGG & 1,020 & 796 & Nicolas et al. [15] \\
\hline & & atpA_R & TGTTCCAGCTACTTTTTTCAT & & & \\
\hline & & atpA_AR & GAGATACCGAAATACCTACG & 970 & & Present study \\
\hline \multirow[t]{2}{*}{ glyA } & Serine hydroxy-methyltransferase & glyA_F & AAAGATAGACAAATTCACGG & 1,042 & 823 & Nicolas et al. [15] \\
\hline & & glyA_R & GGTGATTTATCATCAAAAGG & & & \\
\hline \multirow[t]{2}{*}{$16 \mathrm{~S}$ rRNA } & $16 \mathrm{~S}$ ribosomal RNA & $27 \mathrm{~F}^{-}$ & AGAGTTTGATCCTGGCTCAG & 1,465 & 799 & Universal \\
\hline & & 1492_R & GGTTACCTTGTTACGACTT & & & \\
\hline
\end{tabular}




\section{Phylogenetic analysis}

To construct the phylogenetic relationship of the 21 Flavobacterium strains, we used the molecular evolutionary genetics analysis (MEGA) software package, version 5.05 [16], with the Kimura two-parameter model and bootstrap analyses, based on 1,000 replications. In addition, we compared the genetic similarity of the six housekeeping genes and the 16S rRNA gene between the genus of Flavobacterium using the pair distance of ClustalW (weighted), which was supported by DNASTAR's MegAlign program in Lasergene, version 5.0 (http://www.dnastar. com). The MEGA program was also used to determine the pairwise distances, $\mathrm{G}+\mathrm{C}$ contents, and substitution positions.

\section{Nucleotide sequence accession numbers}

The DNA sequences of the seven amplified Flavobacterium isolates have been deposited in GenBank under accession numbers JX256829-JX256870 (Supplementary Table 1).

\section{Results and Discussion}

In this study, to determine the phylogenetic relationship of the five closely related Flavobacterium species that were previously isolated from a freshwater reservoir in Chonan, Korea [13, 14], we constructed a maximum-liklihood phylogenetic tree, but the tree showed a very low bootstrap value $(<25 \%)$ between them. Previously, Nicolas et al. [15] recommended several housekeeping genes to analyze the phylogenetic relationship among fish-pathogenic F. psychrophilum strains. This approach is called MLSA, which is very useful for distinguishing closely related species and showing population structure. We have chosen seven housekeeping genes as phylogenetic markers-atpA, dnaK, glyA, gyrB, murG, tuf (elongation factor Tu), and $\operatorname{trp} B$ (tryptophan synthase, subunit B) - because these loci contain the largest amounts of polymorphisms among the $50 \mathrm{~F}$ psychrophilum strains [15].

This study is the first to apply Flavobacterium species isolated from a freshwater reservoir. First, we tried to amplify seven housekeeping genes from five Flavobacterium isolates [13, 14], which are closely related to each other based on the 16S rRNA gene. However, we could not amplify the $\operatorname{trp} \mathrm{B}$ gene from our samples from a freshwater reservoir. Therefore, we collected the sequences of six housekeeping genes and the 16S rRNA gene from five Flavobacterium isolates [13, 14], isolated from a freshwater reservoir in Cheonan, Korea, and two Flavobacterium reference strains, $F$. aquatile ATCC 11947 and F. frigidimaris F3-JCM122, as
(A) $16 \mathrm{~S}$ ribosomal RNA

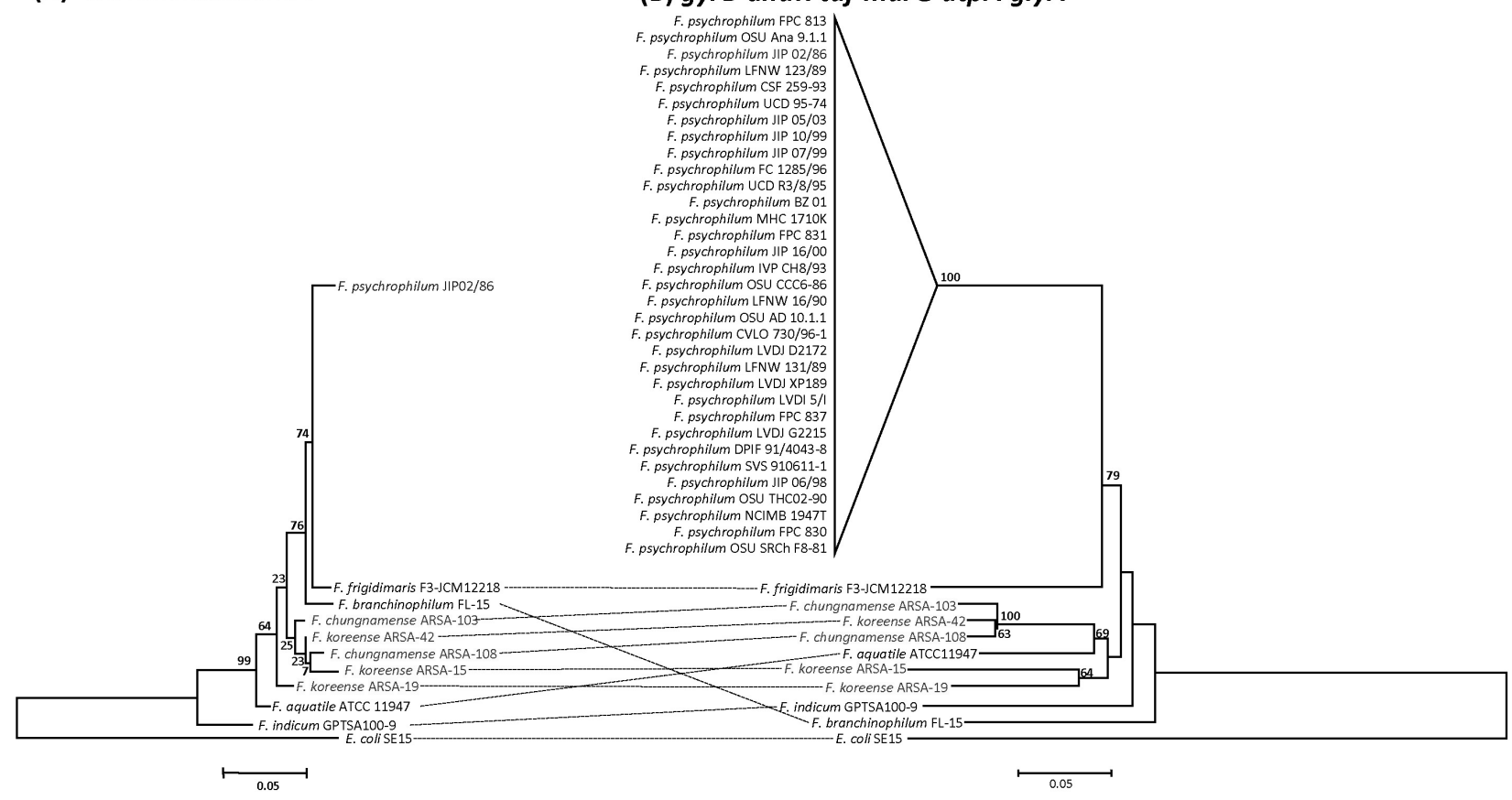

Fig. 1. Maximum-likelihood phylogenetic tree showing the phylogenetic relationship of $16 \mathrm{~S}$ rRNA gene sequences (A) and the concatenated sequences of gyrB-dnaK-tuf-murG-atpA-glyA genes obtained from 42 Flavobacterium species strains and Escherichia coli (B). Numbers on the branches indicate bootstrap values (shown as percentages of 1,000 replications). Scale bar, 0.05 substitutions per nucleotide position. Purple box indicates discordant cluster between two phylogenetic trees. 
interspecies out-groups. In addition, we searched for more Flavobacterium species that were available for the six housekeeping genes from the GenBank database. We found that 52 Flavobacterium species were available for all six housekeeping gene sequences in the database. Among them, 50 Flavobacterium species were $F$. psychrophilum that were identified and studied by Nicolas et al. [15]. The $50 \mathrm{~F}$. psychrophila were assigned to 33 sequence types. Consequently, to evaluate the resolution and efficiency of MLSA, we aligned and trimmed each housekeeping gene sequence (555 bp of gyrB, 680 bp of dnaK, 833 bp of tuf, 725 bp of murG, $796 \mathrm{bp}$ of atpA, and $823 \mathrm{bp}$ of glyA genes) from the five Flavobacterium isolates, 33 distinct $F$. psychrophila, two other Flavobacterium species (F. branchiophilum FL-15 and F. indicum GPTSA100-9), and two reference strains. As shown in Fig. 1, we constructed two different phylogenetic trees of the Flavobacterium species, based on only $16 \mathrm{~S}$ rRNA gene sequences (Fig. 1A) and based on the concatenated sequences of the six housekeeping genes (Fig. 1B). The bootstrap values of the tree branches clearly improved in Fig. 1B compared with those in Fig. 1A. Therefore, we could state that the phylogenetic tree of the genus Flavobacterium, produced by the MLSA approach, is more reliable than the tree based on a single locus (e.g., 16S rRNA gene).

To investigate the nucleotide diversity of each gene among the 10 Flavobacterium species, we analyzed the pairwise distances determined by MEGA5.05 (Table 2). Among the six housekeeping genes and the 16S rRNA gene, the highest average pairwise distance was 0.303 in $m u r G$, while the lowest average pairwise distance was 0.043 in the 16S rRNA gene. We found that the average pairwise distance within the gyrB, dnaK, tuf, atpA, and glyA genes was 0.218, 0.141, 0.115, 0.150 , and 0.215 , respectively, among Flavobacterium species. In addition, we estimated the pairwise distance of the six concatenated housekeeping genes, and thus, the pairwise distance was 0.164 on average. The pairwise distance of the six concatenated housekeeping genes was significantly greater than the pairwise distance of the 16S rRNA gene

Table 2. Average pairwise distances, calculated using Kimura two-parameter model, and average $\mathrm{G}+\mathrm{C}$ content of the seven housekeeping genes in this study

\begin{tabular}{lcc}
\hline \multicolumn{1}{c}{ Locus } & $\begin{array}{c}\text { Average pairwise } \\
\text { distance }\end{array}$ & $\begin{array}{c}\text { Average } \mathbf{G}+\mathbf{C} \\
\text { content (\%) }\end{array}$ \\
\hline gyrB & 0.218 & 36.2 \\
dnaK & 0.141 & 36.3 \\
tuf & 0.115 & 40.0 \\
murG & 0.303 & 35.4 \\
atpA & 0.150 & 40.3 \\
glyA & 0.215 & 38.1 \\
16S rRNA & 0.043 & 48.9 \\
\hline
\end{tabular}

(0.043). Next, we analyzed G + C contents and variable nucleotide sites of six housekeeping genes in our MLSA data and 16S rRNA gene (Table 2). The $\mathrm{G}+\mathrm{C}$ contents of the genes ranged from $35.4 \%$ (murG) to $48.9 \%$ (16S rRNA) (Table 2). The $\mathrm{G}+\mathrm{C}$ content among housekeeping genes was found to be variable.

As a result, this study has demonstrated that MLSA, based on multiloci, produces more reliable phylogenetic trees among Flavobacterium species compared with the tree based on a single locus (e.g., 16S rRNA). When a high number of sequential similarities exist in genetic markers, it might be difficult to identify the phylogenetic relationship between microorganisms of the same genus. Therefore, MLSA will be a good approach to classify the genetic relationships among microorganisms.

\section{Supplementary material}

Supplementary data including one table can be found with this article online at http://www.genominfo.org/src/sm/gni11-272-s001.pdf.

\section{References}

1. Bergey DH, Harrison FC, Breed RS, Hammer BW, Huntoon FM. Manual of Determinative Bacteriology. Baltimore: Williams and Wilkins Co., 1923.

2. Park M, Lu S, Ryu SH, Chung BS, Park W, Kim CJ, et al. Flavobacterium croceum sp. nov., isolated from activated sludge. Int J Syst Evol Microbiol 2006;56(Pt 10):2443-2447.

3. Bernardet JF, Nakagawa Y, Holmes B; Subcommittee on the taxonomy of Flavobacterium and Cytophaga-like bacteria of the International Committee on Systematics of Prokaryotes. Proposed minimal standards for describing new taxa of the family Flavobacteriaceae and emended description of the family. Int J Syst Evol Microbiol 2002;52:1049-1070.

4. Cousin S, Päuker O, Stackebrandt E. Flavobacterium aquidurense sp. nov. and Flavobacterium hercynium sp. nov., from a hard-water creek. Int J Syst Evol Microbiol 2007;57(Pt 2):243-249.

5. Boucher Y, Douady CJ, Sharma AK, Kamekura M, Doolittle WF. Intragenomic heterogeneity and intergenomic recombination among haloarchaeal rRNA genes. J Bacteriol 2004;186: 3980-3990.

6. Gogarten JP, Doolittle WF, Lawrence JG. Prokaryotic evolution in light of gene transfer. Mol Biol Evol 2002;19:22262238.

7. Brady C, Cleenwerck I, Venter S, Vancanneyt M, Swings J, Coutinho T. Phylogeny and identification of Pantoea species associated with plants, humans and the natural environment based on multilocus sequence analysis (MLSA). Syst Appl Microbiol 2008;31:447-460.

8. Delétoile A, Passet V, Aires J, Chambaud I, Butel MJ, Smokvina T, et al. Species delineation and clonal diversity in four Bifidobacterium species as revealed by multilocus sequen- 
cing. Res Microbiol 2010;161:82-90.

9. Margos G, Vollmer SA, Cornet M, Garnier M, Fingerle V, Wilske B, et al. A new Borrelia species defined by multilocus sequence analysis of housekeeping genes. Appl Environ Microbiol 2009;75:5410-5416.

10. Rivas R, Martens M, de Lajudie P, Willems A. Multilocus sequence analysis of the genus Bradyrhizobium. Syst Appl Microbiol 2009;32:101-110.

11. Sakamoto M, Ohkuma M. Identification and classification of the genus Bacteroides by multilocus sequence analysis. Microbiology 2011;157(Pt 12):3388-3397.

12. Hanage WP, Fraser C, Spratt BG. Sequences, sequence clusters and bacterial species. Philos Trans R Soc Lond B Biol Sci 2006; 361:1917-1927.

13. Lee S, Weon HY, Han K, Ahn TY. Flavobacterium dankookense sp. nov., isolated from a freshwater reservoir, and emended de- scriptions of Flavobacterium cheonanense, F. chungnamense, F. koreense and F. aquatile. Int J Syst Evol Microbiol 2012;62(Pt 10):2378-2382.

14. Lee S, Weon HY, Kim SJ, Ahn TY. Flavobacterium koreense sp. nov., Flavobacterium chungnamense sp. nov., and Flavobacterium cheonanense sp. nov., isolated from a freshwater reservoir. $J$ Microbiol 2011;49:387-392.

15. Nicolas P, Mondot S, Achaz G, Bouchenot C, Bernardet JF Duchaud E. Population structure of the fish-pathogenic bacterium Flavobacterium psychrophilum. Appl Environ Microbiol 2008; 74:3702-3709.

16. Tamura K, Peterson D, Peterson N, Stecher G, Nei M, Kumar S. MEGA5: molecular evolutionary genetics analysis using maximum likelihood, evolutionary distance, and maximum parsimony methods. Mol Biol Evol 2011;28:2731-2739. 